\title{
Artificial neural network based unity power factor corrector for single phase DC-DC converters
}

\author{
Hussain Attia \\ Department of Electrical, Electronics and Communications Engineering, School of Engineering, \\ American University of Ras Al Khaimah, United Arab Emirates
}

\begin{tabular}{l} 
Article Info \\
\hline Article history: \\
Received Sep 14, 2019 \\
Revised Feb 27, 2020 \\
Accepted Mar 8, 2020 \\
\hline Keywords: \\
DC-DC converter \\
Duty cycle \\
Load voltage control \\
Total harmonic distortion \\
Simulink \\
Unity power factor controller \\
neural network algorithm \\
Variable loads
\end{tabular}

\section{Article history:}

Received Sep 14, 2019

Revised Feb 27, 2020

Accepted Mar 8, 2020

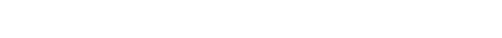

\section{Corresponding Author:}

Hussain Attia,

Department of Electrical, Electronics and Communication Engineering,

American University of Ras Al Khaimah,

Ras Al Khaimah, 10021, United Arab Emirates.

Email: hattia@aurak.ac.ae

\begin{abstract}
Due to the negative effects of the non-linear semiconductor devices and the passive electrical components (inductor and capacitor) in the converter circuits, and that are deteriorating the power factor (PF) and total harmonics distortion (THD) of grid current, this study proposes a novel unity PF correction controller based on a new algorithm of neural network to improve the performance of a single phase boost DC-DC converter with respect to the mentioned concerns. The controller guarantees stable load voltage. The PF corrector, firstly measures the phase shift between grid voltage and grid current waveforms, then through a new artificial neural network (ANN) algorithm, a suitable duty cycle is predicted to guide and control the converter to reduce the phase shift between grid voltage and grid current as possible to have maximum PF which is unity PF, and to improve the THD level of grid current. The proposed system is simulated and evaluated via Simulink of MATLAB, the simulation results are collected at constant duty cycle and at controlled duty cycle through the proposed PF controller using different loads. The presented PF controller guarantees the unity power factor, and enhances the grid alternating current THD.
\end{abstract}

Copyright () 2020 Institute of Advanced Engineering and Science. All rights reserved.

\section{INTRODUCTION}

The passive components, such as inductors and capacitors are playing main roles in electrical systems, this passive component usage increases the reactive power absorption, and consequently increases the electrical losses due to that the power absorbing from grid does not consume in active load but transfer to either electromagnetic field and save in the inductor or save as electrical charge in the capacitor. The mismatch or the phase shift (value and direction) between the grid current waveform and grid voltage waveform provides indication about the level of this losses. In other words, this level can be represented by power factor $(P F)$, which is the rate between the active power (consumed in resistive load) over the apparent power (total power consumed in resistive load and absorbed by the reactive components). So, to reduce or remove the losses in power, $P F$ need to be in higher level which equals to 1 . On the other side, the semiconductor devices, such as different types of power transistors, and diodes which have been involved in many power electronics conversion systems, and because of the nonlinear behaviour of these devices, the grid current waveform shape has been distorted. This current distortion effects negatively the total harmonics distortion (THD) of the grid current. Based on that, the researchers have been focused on increasing the $P F$ and enhancing the THD levels through different studies [1-13].

In study of [1], an automatic $P F$ corrector has designed and proposed via microcontroller to reduce the power losses and the cost as well. In $[2,3]$ power factor correctors have designed and implemented using 
microcontroller integrated circuits. In [2], the microcontroller worked on generating the pulse width modulation pulses to drive the connected DC-DC converter towards increasing the level of power factor. Whereas in [3], a high performance $P F$ corrector has designed and implemented around the microcontroller ATmega328. An effective power factor corrector for a Cuk DC-DC converter has presented in [4], the study focused on $P F$ correcting and improving the Total Harmonics Distortion level of a grid current which is drawn to deliver power to a light emitting diode (LED) lamp.

In [5], a new $P F$ controller has designed and simulated via PWM pulses generator based on variable switching frequency. The controller worked on improving the power factor, controlling the load voltage, and enhancing the THD of grid current. The behaviour of the $P F$ corrector has analysed in [6] in terms of performance effectiveness and THD enhancement by considering non-linear load.

Other studies proposed an intelligent algorithm for high priority $P F$ corrector [7-13], Fuzzy logic control (FLC) based algorithm have proposed in [7-9], whereas recently, Artificial neural network (ANN) based algorithm have proposed in [10-13] for $P F$ correcting. A single-phase $P F$ corrector have presented via two controllers in [7], the controllers are represented by a FLC controller and a predictive controller. In [8], the performance of $P F$ corrector for a boost DC-DC converter has analysed, the proposed $P F$ corrector included three individual controllers; FLC controller, hysteresis controller and proportional integral PI controller. An analytical study has presented in [9] based on simulation results of a PF corrector via FLC. The controller controlled the excitation current of the synchronous motor.

A comparative study in terms of power quality of a power factor corrector is reported in [10], an ANN algorithm is designed in the controller which is integrated with a conventional proportional integral controller. A real-time power factor correction controller has proposed in [11] through an ANN algorithm, which received the instantaneous values of the active and reactive power absorbed by the load, the controller turned $\mathrm{ON}$ or OFF a set of the capacitors in the system. A developed power factor correction controller has presented in [12] to improve the performance of the power system. The study tested the PF corrector effectiveness using a variable load through a fast response algorithm of clustering neural network to automatically control the power factor. In [13], a novel line power factor corrector has presented using a synchronous motor, the excitation current of the motor has controlled for $P F$ increasing through an intelligent controller based on ANN.

This study reports a new intelligent power factor corrector for a single-phase boost DC-DC converter. This paper proposes a new design of an artificial neural network algorithm to predict the suitable duty cycle to have the desired opposite phase shift which is needed for fully matching between grid current and grid voltage, this matching guarantees unity power factor and reduces the distortion in the grid current and enhances the THD of the grid current. The design aspects of the proposed $P F$ correction controller are shown in Section 2, whereas the presented system explanation and main block diagram are shown in Section 3. The collected simulation results are analysed in Section 4. Concluding the outcomes of the presented study is reported in Section 5.

\section{DESIGN ASPECTS OF THE PROPOSED PF CONTROLLER}

Based on the fact of that different loads among resistive, inductive, capacitive, and non-linear might be connected to the grid through the electrical and/or power electronics systems [7]. Resistive loads are consuming an active power from the grid. The inductive and capacitive loads are absorbing a reactive power from the grid and do not consume the power but transfer it to an electromagnetic field through the inductor, or save it in the capacitor as electrical charge. In other words, these reactive components are losing the power by absorbing it from grid without consuming it, in addition, these electrical passive components are shifting the grid current to leg or lead the grid voltage. On the other side, the non-linear semiconductor devices such as MOSFETs transistors, IGBTs transistors, and diodes are distorting the grid current, consequently increasing the Total Harmonics Distortion of the current $[14,15]$. Power Factor is the indication of the rate between the active power $(\mathrm{P})$ to the apparent power $(\mathrm{S})$ that should be in high range which is more than 0.9 , the apparent power $S$ represents vector value includes real value of the active power (Watt) and imaginary value of the reactive power (Volt·Amp) as shown in (1), and explained in Figure 1. To have lower losses system, unity power factor $(P F)$ is necessary as shown in (2).

$$
\begin{aligned}
& S=P+j Q \\
& P F=\frac{P}{S}=1(\text { when } S=P \text { only, or when } Q=0)
\end{aligned}
$$


The grid voltage waveform is representing by (3), and the grid current waveform can be represented by (4) due to the phase shift between the grid voltage and the grid current. The phase shift (value and direction) between the two waveforms is depending on the value and the type of the impedance. In other words, as shown in Figure 1, the phase shift between the grid voltage and grid current represents the same phase shift of the equivalent impedance, and the value of the power factor $P F$ can be calculated by (5).

$$
\begin{aligned}
& V_{\text {grid }}=V_{m} \sin (w t) \\
& I_{\text {grid }}=I_{m} \sin (w t+\theta)
\end{aligned}
$$

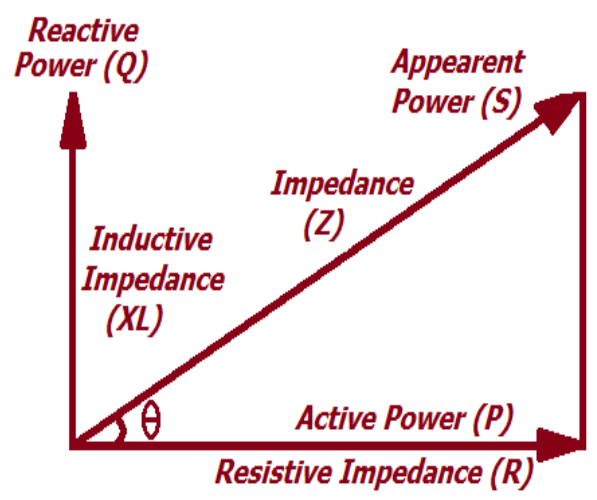

Figure 1. Apparent power $S$ contents active power $P$ and reactive power $Q$

Where $V_{\text {grid }}, I_{\text {grid }}, V_{m}, I_{m}$, and $\theta$ represent grid voltage, grid current, peak value of grid voltage, peak value of the grid current, and phase shift between grid voltage and grid current waveforms, whereas $w$ equals to $2 \pi f_{o}$, and $f_{o}$ is the grid frequency, $\mathrm{t}$ is the time $(\mathrm{sec})$.

$$
P F=\frac{\text { Active Power }}{\text { Appearent Power }}=\frac{P}{S}=\operatorname{Cos}(\theta)
$$

Power factor $P F$ can be one when having zero phase shift between the apparent power and active power. In terms of converter, to have $P F$ improvement, the converter drive pulses which are pulse width modulation technique based pulses can be controlled. The width of the PWM pulses can be controlled based on ANN predicting to the duty cycle which is required to compensate the phase shift between the grid voltage and the grid current. Based on the fact of that the artificial neural network ANN can quickly predict the suitable numerical value by considering the instantaneous numerical values of the input variables of the related system's parameters [16-18]. So, a new ANN algorithm has designed in this paper to predict the suitable duty cycle to have 100 percent matching between the grid voltage and grid current that consequently lead to have unity $P F$. Neural network can be designed and implemented by involving one input layer, one hidden layer, and one output layer, whereas there is possibility to involve more than one hidden layer. Neuron is the fundamental unit in the ANN, Figure 2 shows the neuron's contents and processing stages which are representing by input variables receiving stage, variables weighting stage, then adder stage to have $Z$ value as shown in (6). This value is manipulated by one of the three activation functions as shown in (7-9).

$$
\begin{aligned}
& Z=\sum_{n=1}^{N} W_{n} X_{n}+B \quad \text { (Variables Weighting \& Addition) } \\
& y_{n}=f(z) \quad \text { (Linear activation function) } \\
& f(z)=\frac{1}{1+\exp ^{-z}} \quad \text { (Sigmoidal activation function) }
\end{aligned}
$$




$$
f(z)=\frac{1+\exp ^{-2 z}}{1-\exp ^{-2 z}}(\text { Hyperbolic activation function }
$$

The accuracy of the designed ANN algorithm can be evaluated by monitoring the value of the mean square error $(M S E)$ which reflects the result of error level between the target value and the predicted value as explained in $(10,11)$.

$$
\begin{aligned}
& M S E=\frac{1}{q} \sum_{k=1}^{q} e(k)^{2} \\
& M S E=\frac{1}{q} \sum_{k=1}^{q}[t(k)-a(k)]^{2}
\end{aligned}
$$

Where $q$ is the elements number of the input vector, $e(k)$ is the error value, $t(k)$ is the target value, and $a(k)$ is the output vector value which is predicted by the neural network algorithm [19].

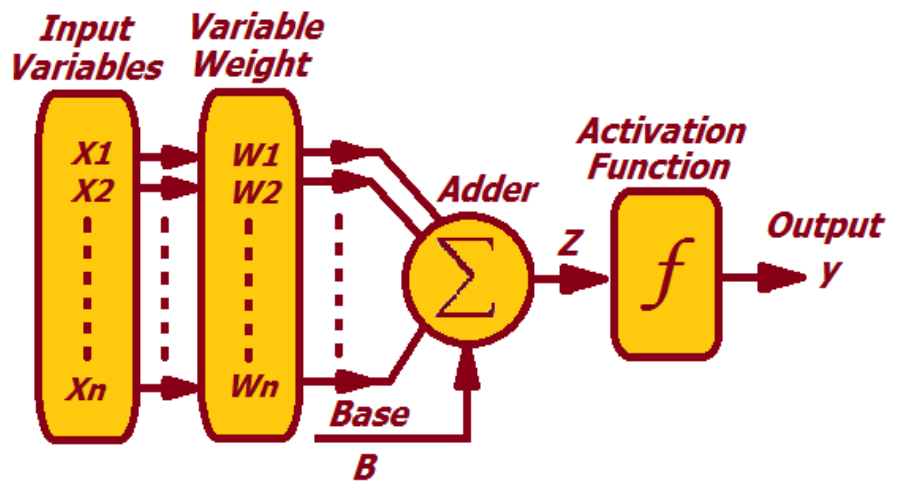

Figure 2. The neuron representation

\section{DESIGN OF THE PRESENTED ANNBASED PF CORRECTOR}

The paper design mainly focuses on increasing the $P F$ of the converter system to the aim of unity power factor, and at the same time to enhance the THD level of the grid current. Figure 3 shows the main diagram of the presented power factor corrector. The system blocks are divided to two groups, controlling blocks and power electronics blocks. The controlling blocks are starting by a measuring block which receives the instantaneous values of the grid voltage and grid current, calculates the phase shift $(\theta)$ between the grid voltage and current waveforms and calculates the power factor $P F$ value using (3)-(5). The instantaneous value of the phase shift enters the artificial neural network block, and at the same time, the ANN block receives the absolute value of the grid voltage. The function of the designed ANN is to predict the initial value of duty cycle $D$, the final value of duty cycle is found after considering the error signal between the load current and the reference current and the error signal between the load voltage and the reference voltage. The final value of the duty cycle $D$ enforces the converter to have full matching between the grid voltage and the grid current. The other meaning of full matching is the phase shift is zero and the power factor $(\cos (\theta))$ is one. The designed ANN includes three hidden layers in addition to one input layer and one output layer as shown in Figure 4. Pulse Width Modulation (PWM) pulses generator generates the drive pulses to the involved boost DC-DC converter [20-25]. The second group of blocks in the proposed system involves the power electronics device which is the boost DC-DC converter, in addition to the electrical resistive load. The converter is designed in this study through the design steps of [26], in which the converter output load voltage $\left(V_{O}\right)$ is relate to the converter input voltage $\left(V_{i n}\right)$ by considering the Duty cycle $(D)$ value $(12)$. The electrical load used in this study is a variable resistive load with three resistances of $160 \Omega, 120 \Omega$, and $80 \Omega$.

$$
V_{o}=\frac{1}{1-D} V_{i n}
$$




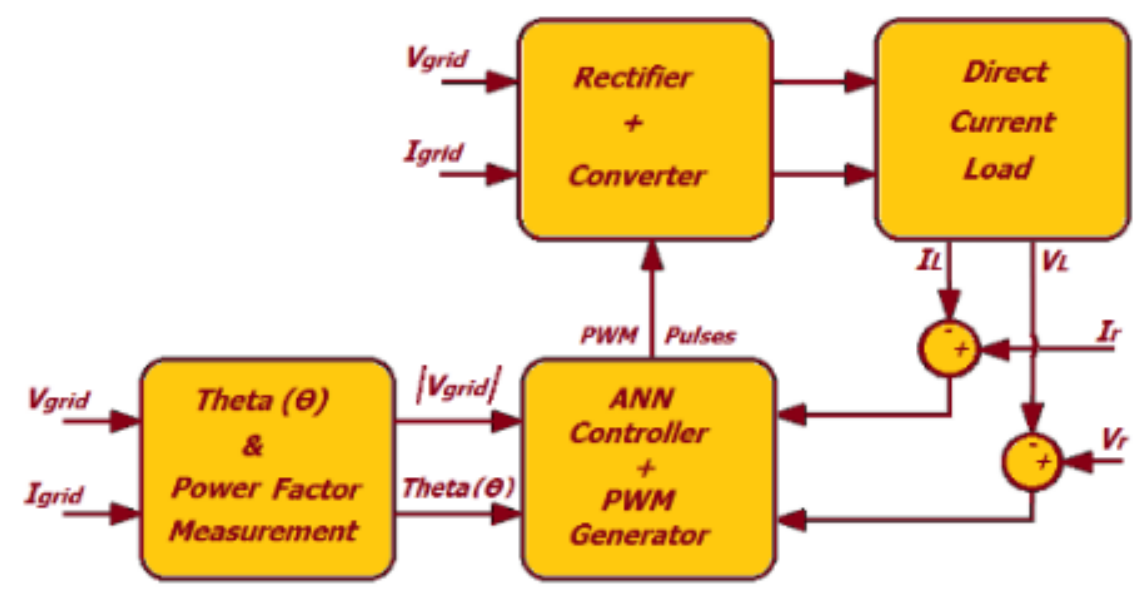

Figure 3. The main block diagram of the proposed $P F$ corrector

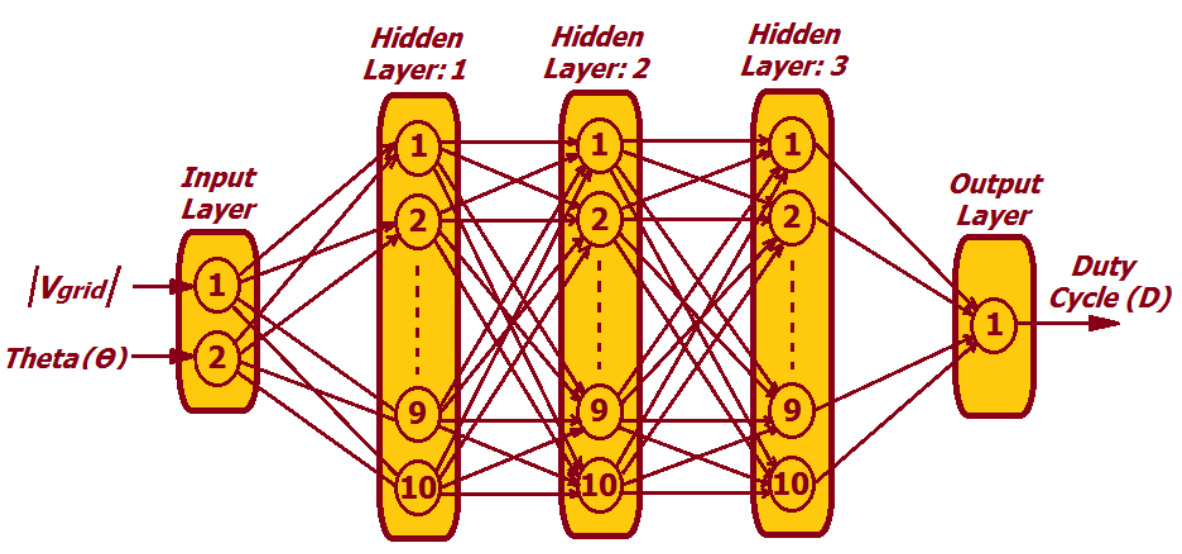

Figure 4. The proposed controlling neural network algorithm

\section{PF CONTROLLER SIMULATION AND SIMULATION RESULTS}

The proposed $P F$ corrector is simulated via MATLAB/Simulink, the designed algorithm of the neural network is simulated which includes input layer of two neurons, three hidden layers of ten neurons each, and output layer of one neuron as shown in Figure 5, whereas the ANN accuracy is shown in Figure 6 and evaluated through the mean square error $(M S E)$ of the algorithm. On the other hand, the converter parameters setting is shown in Table 1, in which, the considered switching frequency is $12 \mathrm{kHz}$. The system performance is evaluated, firstly via constant $60 \%$ duty cycle and variable resistive loads $(160 \Omega, 120 \Omega$, $80 \Omega$ ) during 3 seconds simulation time. The simulation time is divided equally into three times of one second for each load value. Grid voltage of $\mathrm{V}_{\text {rms }}$ value $110 \mathrm{~V} / 60 \mathrm{~Hz}$ and grid current waveforms are shown in Figure 7, it's clearly noticeable the phase shift between grid voltage and grid current, and also the distortion of the grid current which is increased during the increasing of the load current. The total harmonics distortion (THD\% $=44.57 \%$ ) and the high levels of the low order harmonics of the grid current at $80 \Omega$ load are also clear shown in Figure 8 . The system behavior in terms of load voltage is shown in Figure 9, the overshoot of load voltage at beginning of converter response is clearly monitored. At the same time the load voltage level is varying with different values during load variation. The $P F$ levels all are monitored and recorded in Table 2 during the constant duty cycle, and at the controlling function later.

The system performance is evaluated and monitored through the proposed controller for same resistive loads and same simulation time divisions. Grid voltage and grid current are shown in Figure 10, the matching between the grid voltage and current is clearly noticeable and positively affects the $P F$ improving, and enhances the low order harmonics and THD of grid current as well as shown in Figure 11, in which the THD level at load $80 \Omega$ equals to (THD\% $=7.68 \%$ ). The merit of the proposed controller in terms of controlling and stabilizing the load voltage at different loads is shown in Figure 12. Via the presented controller, the overshoot in load voltage is completely removed, and the load voltage is stabilized during the load 
varying. Figure 13 shows system performance during 1 second simulation time, in first part of which the system works with constant $60 \%$ duty cycle, and after $0.55 \mathrm{sec}$, the system works under the proposed $P F$ corrector role. It is very clear the positive effect of the proposed controller on the system performance in terms of phase shift reduction between grid voltage and grid current, and in terms of shape of grid current waveform. Table 2 shows all records of $P F$ levels, load voltages, and THD for all loads, with and without inserting the proposed $P F$ corrector.

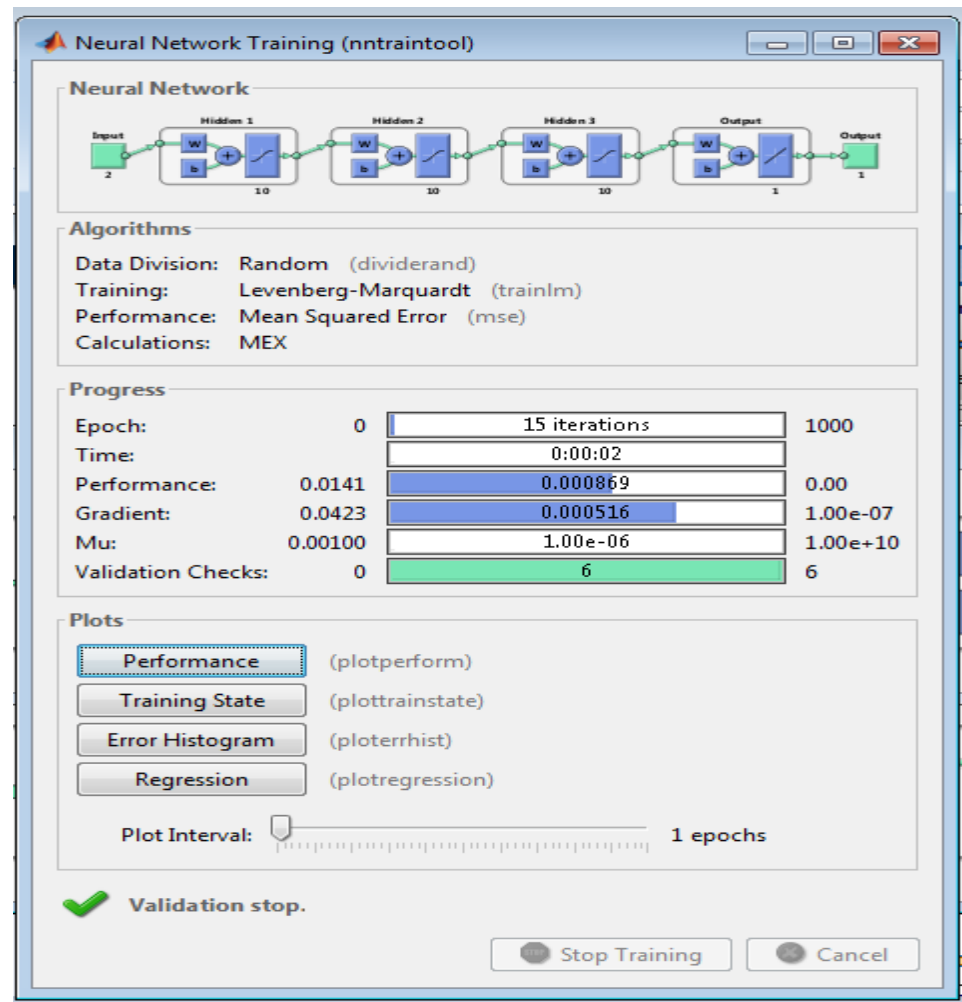

Figure 5. The simulated Feed-forward ANN algorithm

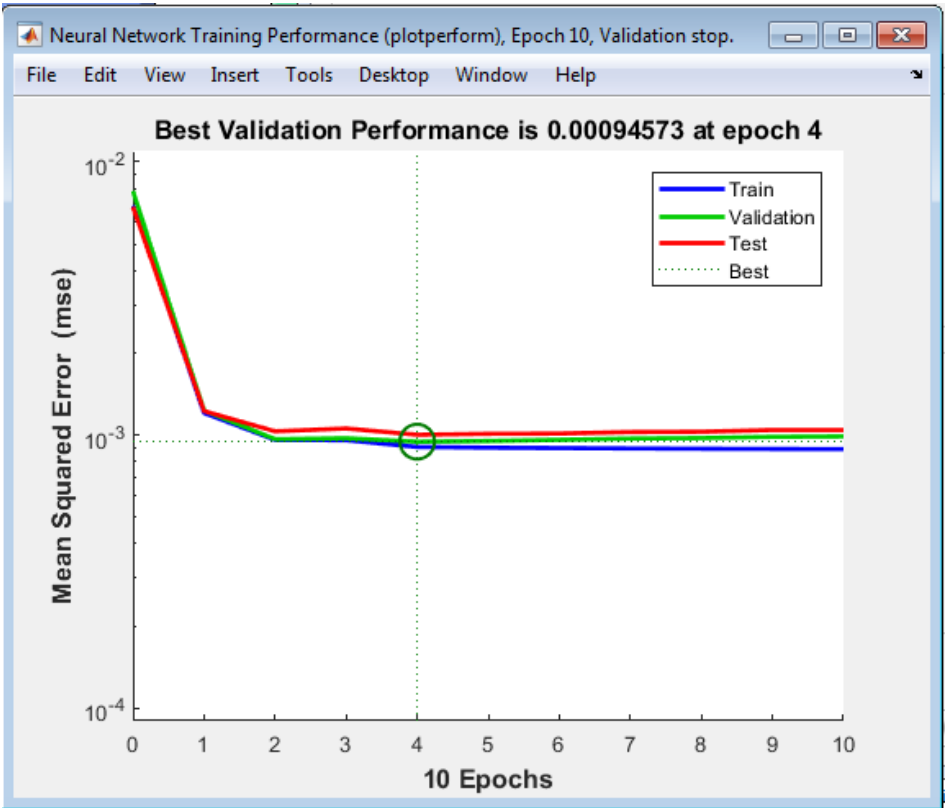

Figure 6. The performance of the simulated ANN algorithm 
Table 1. Designed parameters of the DC-DC converter

\begin{tabular}{cc} 
Parameter Name & Parameter Value \\
Resistive Load & $80 \Omega, 120 \Omega, 160 \Omega$, \\
Capacitor & $1200 \mu \mathrm{F}$ \\
Inductor & $12 \mathrm{mH}$ \\
Switching Frequency & $12 \mathrm{kHz}$ \\
Duty Cycle & 0.5 \\
\hline
\end{tabular}

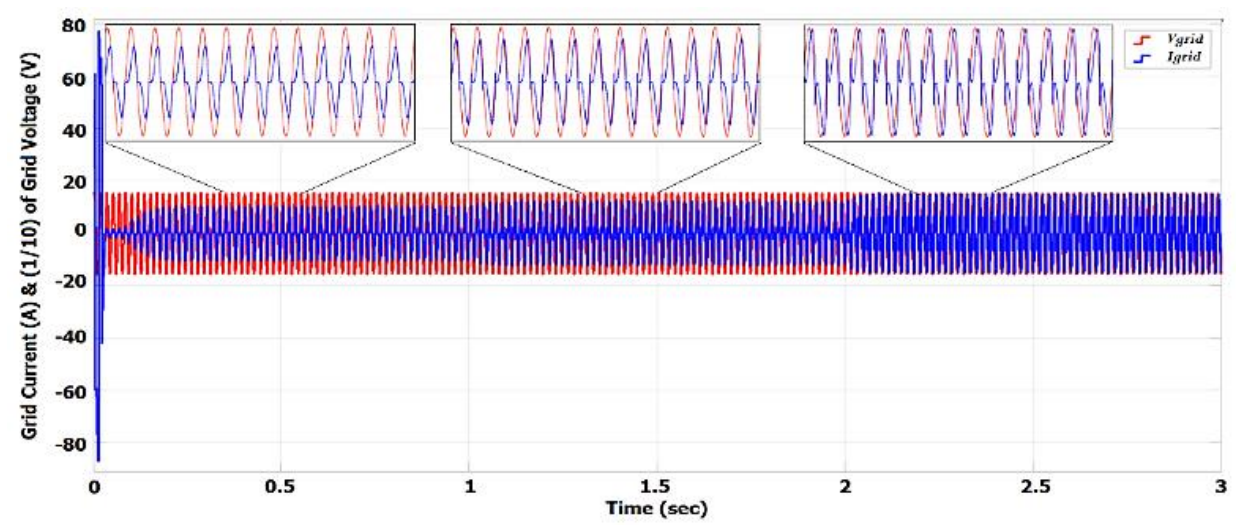

Figure 7. Grid voltage and grid current waveforms with zoom in for each load $160 \Omega$, $120 \Omega$, and $80 \Omega$ respectively at $60 \%$ constant duty cycle

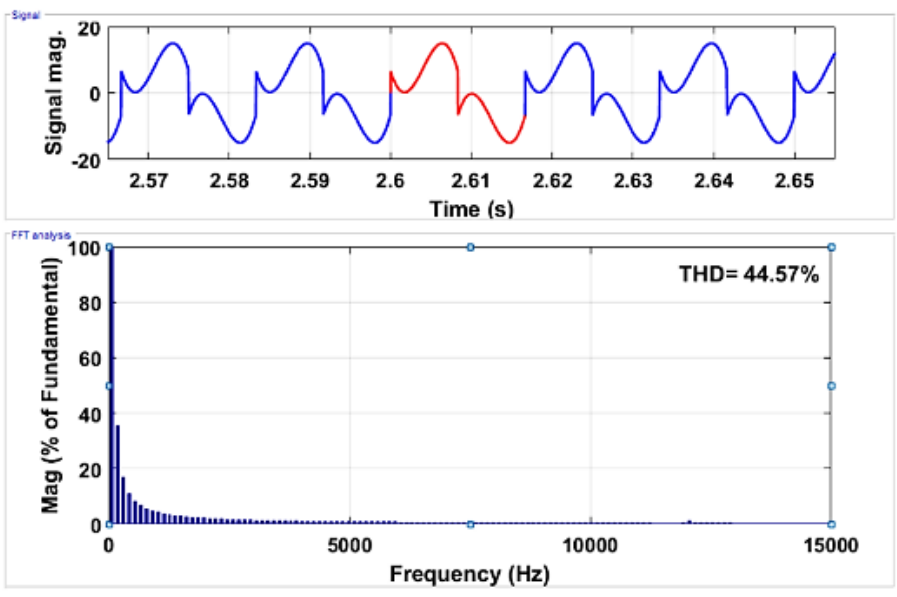

Figure 8. Fast Fourier transform and harmonic spectrum content in grid current load $80 \Omega$ and at $60 \%$ constant duty cycle

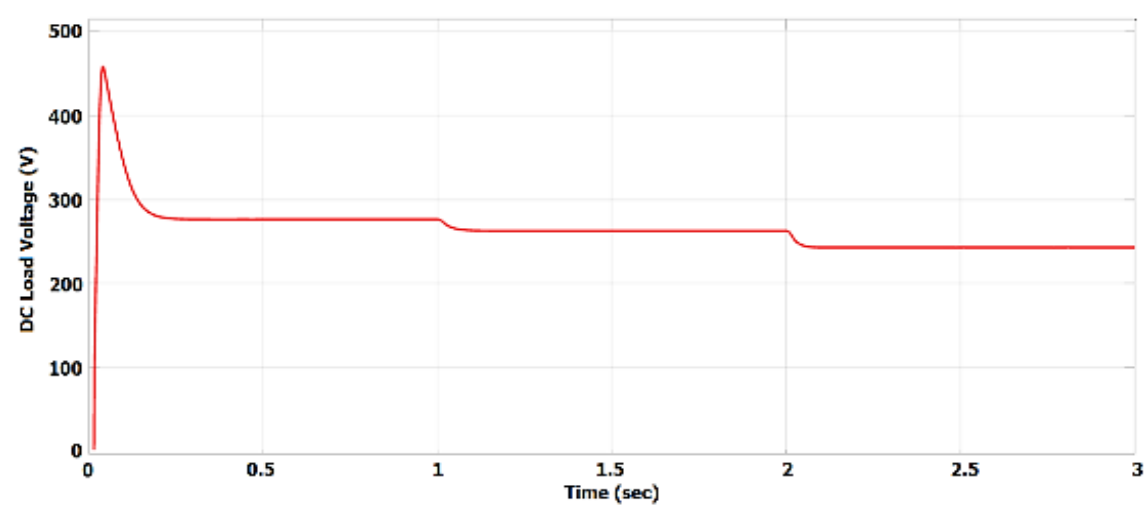

Figure 9. Load voltage at load $160 \Omega, 120 \Omega$, and $80 \Omega$ respectively and at $60 \%$ constant duty cycle 


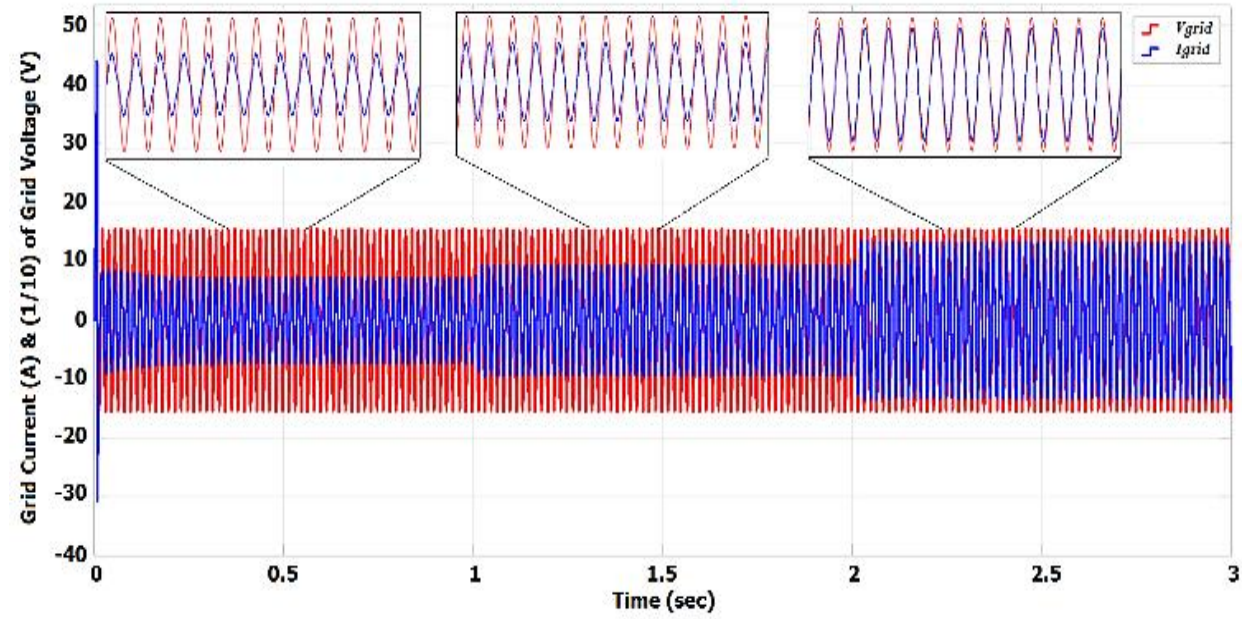

Figure 10. Grid voltage and grid current waveforms with zoom in for each load $160 \Omega$, $120 \Omega$, and $80 \Omega$ respectively via the proposed $P F$ controller

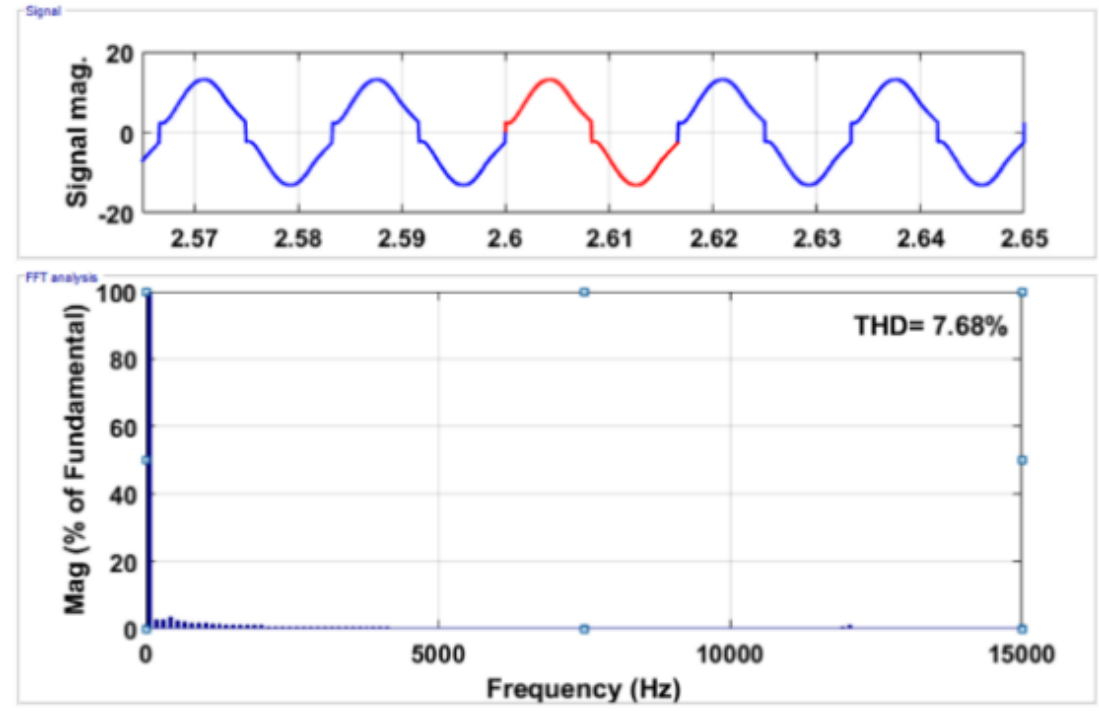

Figure 11. Fast Fourier transform and harmonic spectrum content in grid current load $80 \Omega$ via the proposed $P F$ corrector

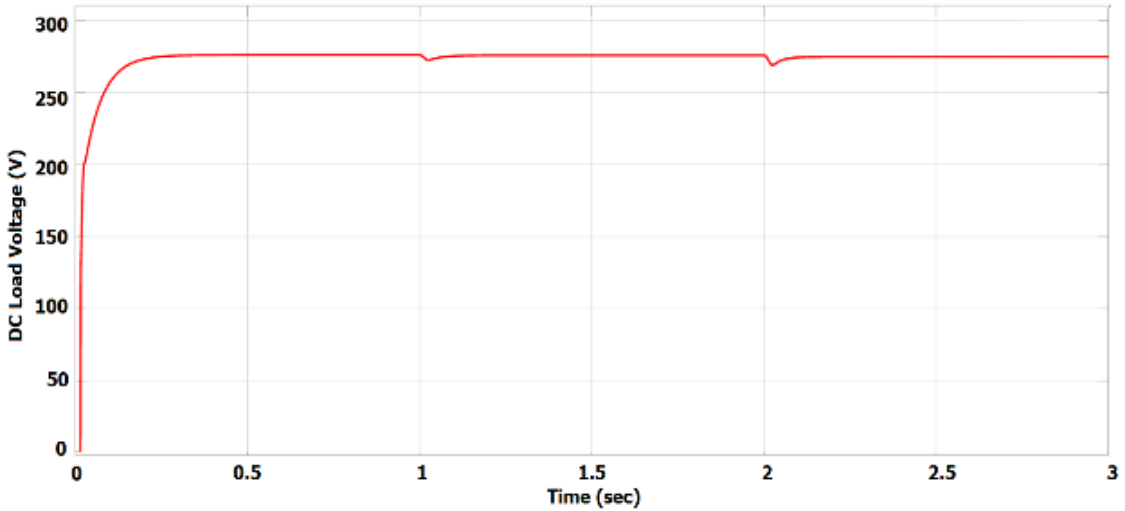

Figure 12. Load voltage at load $160 \Omega, 120 \Omega$, and $80 \Omega$ respectively and via proposed $P F$ corrector 


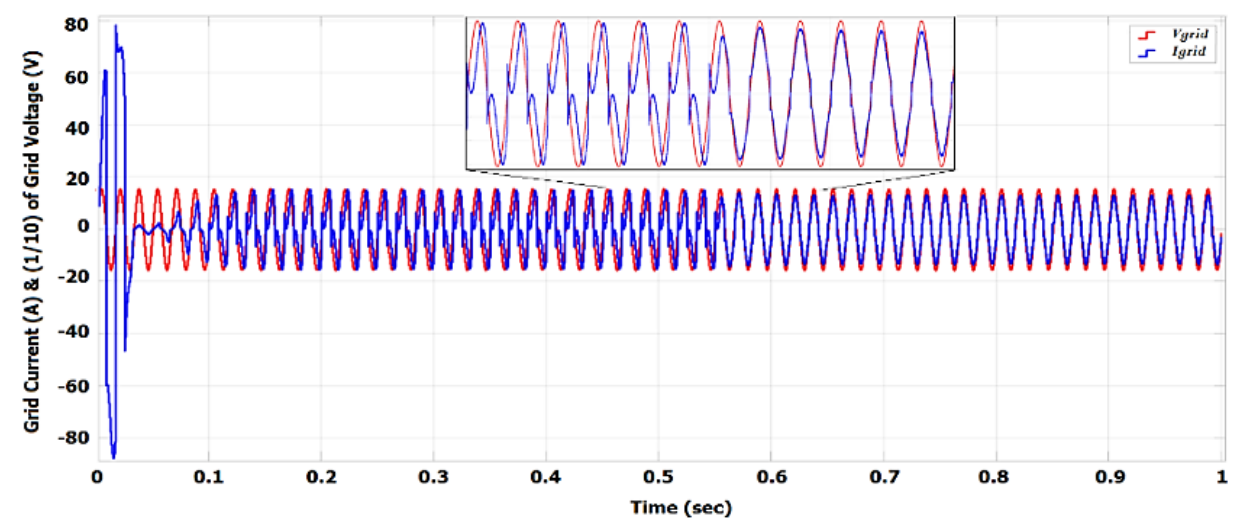

Figure 13. The proposed $P F$ corrector performance after $0.55 \mathrm{sec}$ at load $80 \Omega$

Table 2. Simulation results of power factor, load voltage, and THD using different loads through constant $60 \%$ duty cycle and ANN controlled duty cycle

\begin{tabular}{|c|c|c|c|c|}
\hline \multicolumn{2}{|c|}{ Parameters } & $\begin{array}{c}\text { Variable Resistive } \\
\text { Load RL }=80 \Omega\end{array}$ & $\begin{array}{l}\text { Variable Resistive } \\
\text { Load RL }=120 \Omega\end{array}$ & $\begin{array}{l}\text { Variable Resistive } \\
\text { Load RL }=160 \Omega \\
\end{array}$ \\
\hline \multirow[t]{2}{*}{ Power factor } & $\begin{array}{l}\text { Without control } \\
\text { Fixed } D=0.6\end{array}$ & 0.8338 & 0.8194 & 0.8394 \\
\hline & Controlled Duty Cycle D & 0.9993 & 1 & 0.9994 \\
\hline $\begin{array}{l}\text { Resistive load } \\
\text { Voltage (V) }\end{array}$ & $\begin{array}{l}\text { Without control } \\
\text { Fixed } D=0.6\end{array}$ & $242.8 \mathrm{~V}$ & $262.6 \mathrm{~V}$ & $276.2 \mathrm{~V}$ \\
\hline \multirow{3}{*}{$\begin{array}{c}\text { Total harmonics distortion } \\
\text { THD\% }\end{array}$} & Controlled Duty Cycle D & $275.4 \mathrm{~V}$ & $276.1 \mathrm{~V}$ & $276.3 \mathrm{~V}$ \\
\hline & $\begin{array}{l}\text { Without control } \\
\text { Fixed } D=0.6\end{array}$ & $44.57 \%$ & $34.27 \%$ & $36.33 \%$ \\
\hline & Controlled Duty Cycle D & $7.68 \%$ & $8.68 \%$ & $11.34 \%$ \\
\hline
\end{tabular}

\section{CONCLUSION}

This paper presented a new power factor correction controller with load voltage controlling ability for single phase boost DC-DC converter systems, the presented controller worked also on enhancing the Total Harmonic Distortion level of the grid current. The controller considered the merits of the artificial neural network algorithms in terms of fast and accurate response for predicting the numerical values of the related parameters. This study designed, MATLAB simulated, and results analysed of a new $P F$ corrector, and the system performance is evaluated in terms of $P F$ level, load voltage regulating, harmonics spectrum, and THD level of grid current. The collected records indicate the effectiveness of the proposed controller which guaranteed the unity power factor, and stabilized the load voltage with clearly noticeable THD enhancing for all direct current loads $80 \Omega, 120 \Omega, 160 \Omega$. The high performance of the proposed controller promises the successfulness of the future practical prototype.

\section{ACKNOWLEDGEMENTS}

The authors appreciate the financial support provided by school of engineering, American University of Ras Al Khaimah - UAE, www.aurak.ac.ae/en/school-of-engineering/

\section{REFERENCES}

[1] A. R. Yadav, S. S. Waghmode, G. B. Gawade, S. S. Zinjade and P. T. Patil, "A review on microcontroller based automatic power factor correction," International Journal of Advanced Research in Electrical, Electronics and Instrumentation Engineering, vol. 5, no. 3, pp. 1517-1520, 2016.

[2] K. K. Jha, B. Mahato, P. Prakash and K. C. Jana, "Hardware implementation of single phase power factor correction system using micro-controller," International Journal of Power Electronics and Drive Systems (IJPEDS), vol. 7, no. 3, pp. 790-799, 2016.

[3] N. H. Ishak, M. N. Zainodin, N. A. Salim, F. M. T. Tawi and A. H. M. Saod, "A design of an automatic single phase power factor controller by using arduino uno rev-3," Applied Mechanics and Materials, vol. 785, pp 419-423, 2015.

[4] D. Saravanan and M. Gopinath, "A novel power factor correction modified bridge less-CUK converter for LED lamp applications," International Journal of Power Electronics and Drive Systems(IJPEDS), vol. 7, no. 3, pp. 880-891, 2016. 
[5] M. R. Kumar, D. Lenine and C. S. Babu, "A variable switching frequency with boost power factor correction converter," TELKOMNIKA Telecommunication, Computing, Electronics and Control, vol. 9, no.1, pp. 47-54, 2011.

[6] R. A. Rani, S. Saat, Y. Yusop, H. Husin, F. K. A. Rahman and A. A. Isa, "The effects of total harmonics distortion for power factor correction at non-linear load," International Journal of Power Electronics and Drive Systems (IJPEDS), vol. 7, no. 2, pp. 543-550, 2016.

[7] A. Kessal, "Combined fuzzy and predictive controller for unity power factor converter," International Journal of Electrical and Computer Engineering (IJECE), vol. 8, no. 9, pp. 1541-1546, 2014.

[8] A. Bhakthavachala, S. Tara kalyani, K. Anuradha, Nukala Vengaiah, "Fuzzy logic controller based unity power factor correction of boost converter," IOSR Journal of Electrical and Electronics Engineering (IOSR-JEEE), vol. 12 , no. 6 , pp. 52-58, 2017.

[9] G. Ahmet, Ö. F. Keçecioğlu, H. Açıkgöz, C. Yıldız and M. Şekkeli, "Simulation study on power factor correction controlling excitation current of synchronous motor with fuzzy logic controller," International Journal of Intelligent Systems and Applications in Engineering, vol. 4, pp. 229-233, 2016.

[10] N. Ramchandra, and M. Kalyanchakravarthi, "Neural network based unified power quality conditioner," International Journal of Modern Engineering Research.(IJMER), vol. 2, no. 1, pp. 359-365, 2012.

[11] C. J. Salaan, and N. R. Estoperez, "An artificial neural network based real-time reactive power controller," Proceedings of the World Congress on Engineering and Computer Science, vol. 1, 2011.

[12] A. A. Abed, "Improved power factor of electrical generation by using clustering neural network," International Journal of Applied Engineering Research, vol. 13, no. 7. pp. 4633-4636, 2018.

[13] S. Sagiroglu, I. Colak and R. Bayindir, "Power factor correction technique based on artificial neural networks," Energy Conversion and Management, vol. 47, no. 18-19, pp. 3204-3215, 2006.

[14] M. Malinowski, M. Jasinski, M. P. Kazmierkowski, "Simple direct power control of three-phase PWM rectifier using space-vector modulation (DPCSVM)," IEEE Transactions on Industrial Electronics, vol. 51, no. 2, pp. 447-454, 2004.

[15] M. Ochiai and H. Matsuo, "An AC/DC converter with high power factor," IEEE Transactions on Industrial Electronics, vol. 50, no. 2, pp. 356-361, 2003

[16] S. D. Stallon, K. V. Kumar andS. S. Kumar, "High efficient module of boost converter in PV module," International Journal of Electrical and Computer Engineering (IJECE), vol. 2, no. 6, pp. 758-781, 2012.

[17] H. Attia, "Supplying DC electricity to the isolated dwellings through MPP tracked PV system based on artificial neural network," Proceedings of the 6th International Conference of Control, Dynamic Systems, and Robotics, 2019.

[18] H. A. Attia, "High performance PV system based on artificial neural network MPPT with PI controller for direct current water pump applications," International Journal of Power Electronics and Drive Systems, vol. 10, no. 3, pp. 1329-1338, 2019.

[19] M. Hudson, M., T. Hagan and H. B. Demuth, "Neural network ToolboxTM, 2013: User's Guide," MatlabMathWorks, 2014.

[20] H. A. Attia and F. delAma Gonzalo, "Stand-alone PV System with MPPT function based on fuzzy logic control for remote building applications," International Journal of Power Electronics and Drive System, vol. 10, no. 2, pp. 842-851, 2019.

[21] M. Nagaiah, and K. C. Sekhar, "Analysis of fuzzy logic controller based bi-directional DC-DC converter for battery energy management in hybrid solar/wind micro grid system," International Journal of Electrical and Computer Engineering, vol. 10, no. 3, pp. 2271-2284, 2020.

[22] B. E. Elnaghi, M. E. Dessouki, M. N. Abd-Alwahab, Elwy E. Elkholy4, "Development and implementation of two-stage boost converter for single-phase inverter without transformer for PV systems," International Journal of Electrical and Computer Engineering (IJECE), vol. 10, no. 1, pp. 660-669, 2020.

[23] A. S. Samosir, H. Gusmedi, S. Purwiyanti and E. Komalasari, "Modeling and simulation of fuzzy logic based maximum power point tracking (MPPT) for PV application," International Journal of Electrical and Computer Engineering (IJPEDS), vol. 8, no. 3, pp. 1315-1323, 2018.

[24] H. Attia, "Fuzzy logic controller effectiveness evaluation through comparative memberships for photovoltaic maximum power point tracking function," International Journal of Power Electronics and Drive Systems (IJPEDS), vol. 9, no. 3, pp. 1147-1156, 2012.

[25] M.W. Umar, N.B. Yahaya, Z.B. Baharuddin, "PWMDimming control for high brightness LED based automotive lighting applications," International Journal of Electrical and Computer Engineering (IJECE), vol.7, no.5, pp. 2434-2440, 2017.

[26] P. Srinivas, "Implementation of PWM control of DC split converter fed switched reluctance motor drive," International Journal of Electrical and Computer Engineering (IJECE), vol. 7, no. 2, pp. 604-609, 2017.

\section{BIOGRAPHY OF AUTHOR}

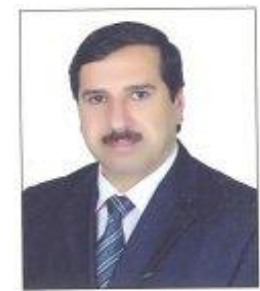

Hussain Attia earned his Ph.D. degree in power electronics from University of Malaya, Kuala Lumpur, Malaysia, and M.Sc. degree in electronic engineering from the University of Technology, Baghdad, Iraq. Hussain's research interests include power electronics, AC \& DC Drives, PWM Inverters (single phase \& three phases), harmonics reduction techniques, and intelligent control. 